\title{
Factors Affecting Recovery Time of Pulmonary Function in Hospitalized Patients With Acute Asthma Exacerbations
}

\author{
Hyo-Jung Kim, Jaemoon Lee, Jung-Hyun Kim, So-Young Park, Hyouk-Soo Kwon, Tae-Bum Kim, Hee-Bom Moon, \\ You Sook Cho*
}

Department of Allergy and Clinical Immunology, Asan Medical Center, University of Ulsan College of Medicine, Seoul, Korea

\begin{abstract}
This is an Open Access article distributed under the terms of the Creative Commons Attribution Non-Commercial License (http://creativecommons.org/licenses/by-nc/3.0/) which permits unrestricted non-commercial use, distribution, and reproduction in any medium, provided the original work is properly cited.
\end{abstract}

Purpose: Prolonged recovery time of pulmonary function after an asthma exacerbation is a significant burden on asthmatics, and management of these patients needs to be improved. The aim of this study was to evaluate factors associated with a longer recovery time of pulmonary function among asthmatic patients hospitalized due to a severe asthma exacerbation. Methods: We retrospectively reviewed the medical records of 89 patients who were admitted for the management of acute asthma exacerbations. The recovery time of pulmonary function was defined as the time from the date each patient initially received treatment for asthma exacerbations to the date the patient reached his or her previous best FEV1\% value. We investigated the influence of various clinical and laboratory factors on the recovery time. Results: The median recovery time of the patients was 1.7 weeks. Multiple linear regression analysis revealed that using regular inhaled corticosteroids (ICS) before an acute exacerbation of asthma and concurrent with viral infection at admission were associated with the prolonged recovery time of pulmonary function. Conclusions: The prolonged recovery time of pulmonary function after a severe asthma exacerbation was not shown to be directly associated with poor adherence to ICS. Therefore the results indicate that an unknown subtype of asthma may be associated with the prolonged recovery of pulmonary function time after an acute exacerbation of asthma despite regular ICS use. Further prospective studies to investigate factors affecting the recovery time of pulmonary function after an asthma exacerbation are warranted.

Key Words: Asthma; acute exacerbation; pulmonary function tests; inhaled corticosteroid; phenotype

\section{INTRODUCTION}

Asthma is characterized by episodic bronchial obstruction that is typically reversible. ${ }^{1}$ Some patients experience severe asthma exacerbations during their clinical course, which is a significant burden..$^{1-4} \mathrm{~A}$ variety of factors, such as viral upper respiratory infection, pollens, air pollution, and poor adherence to medication, can induce asthma exacerbations. ${ }^{1,2,5,6}$ The introduction of safe and effective inhaled corticosteroids (ICSs) has enabled marked improvement in the control of asthma for most patients. Indeed, ICS maintains satisfactory asthma control and also prevents a large proportion of hospital admissions due to an asthma exacerbation.

Due to the heterogeneous nature of asthma, the clinical course of an asthma exacerbation is diverse. A previous study reported that several parameters of the pulmonary function test (PFT) usually return to their baseline values within 1-2 weeks, even after a severe asthma exacerbation, ${ }^{8}$ but in practice we witness a wide range of recovery times between administration of therapeutic agents and full recovery from asthma exacerba- tions. Prolonged recovery from asthma exacerbations is a high burden on the patient that can be associated with a poorer prognosis of asthma. ${ }^{9,10}$ However, factors associated with prolonged recovery of asthma exacerbations have not been investigated so far.

Variable recovery times after asthma exacerbations may be associated with different responsiveness to corticosteroids. Some of the studies demonstrated significant variability in patient response to ICS; $25 \%-35 \%$ of patients with asthma showed

Correspondence to: You Sook Cho, MD, PhD, Division of Allergy and Clinical Immunology, Department of Internal Medicine, Asan Medical Center, University of Ulsan College of Medicine, 88 Olympic-ro 43 gil, Songpa-gu, Seoul 05505, Korea.

Tel: +82-2-3010-3280; Fax: +82-2-3010-6969; E-mail: yscho@amc.seoul.kr Received: December 7, 2015; Revised: March 15, 2016;

Accepted: March 25, 2016

- This study was supported by a grant from the Korean Health Technology R\&D Project, Ministry of Health Et Welfare, Republic of Korea (H113C-2628-030014 and H113C-1962-010014).

- There are no financial or other issues that might lead to conflict of interest. 
little improvement in FEV1\% and/or bronchial hyper-responsiveness (BHR). ${ }^{11,12}$ Others have investigated factors associated with prolonged recovery time after an asthma exacerbation and reported that allergic rhinitis, older patient age, and poor asthma control status significantly affected the recovery time of pulmonary function. ${ }^{13,14}$ Nevertheless, further studies are needed to clarify precise causes linked to delayed recovery from an exacerbation because differences in ethnic background or socioenvironmental factors may have an impact on exacerbation outcome.

In this study, we investigated factors associated with the prolonged recovery time of pulmonary function after administration of appropriate treatment for a severe acute asthma exacerbation. We defined 'severe' asthma exacerbations as exacerbations which needed administration of systemic steroids and hospitalization.

\section{MATERIALS AND METHODS}

\section{Study population and design}

We retrospectively reviewed the medical records of 113 patients who were admitted for the management of asthma exacerbations at our institution, a single university hospital, between October 2009 and December of 2014. Of the study subjects, we included only 89 who underwent pulmonary function tests serially during hospitalization and after discharge until they recovered from their asthma exacerbations. Hospitalization was defined as at least 1 day of hospital stay. The recovery time of pulmonary function was defined as the time lapse from the admission and initial administration of medications to the date the patient reached the best FEV1\% predicted value after an asthma exacerbation.

The PFT was performed according to the American Thoracic Society Guidelines. Standard instructions were given prior to the examination which was conducted by an experienced technician. The PFT was serially performed for all study subjects from the time of admission until they reached the best FEV1\% predicted. The PFT was performed at least twice a week during hospitalization and was performed every week after discharge until the patient reached the best FEV1\% predicted. The full recovery time was defined as the time when the value of FEV1\% predicted was in the range of $\pm 10 \%$ of the patient's best value (during the year prior to an acute exacerbation) was reached.

Baseline demographic data and various clinical parameters of the study patients were evaluated. Previous history of acute exacerbations, use of controller medications, use of systemic corticosteroids, previous history of exacerbations requiring hospitalization in the past year, duration of asthma, smoking status, and seasonal tendency toward an acute exacerbation were evaluated as possible variables associated with the prolonged recovery time of pulmonary function after an asthma exacerbation. Additionally, we evaluated co-morbid conditions and oth- er medical conditions in the study patients, including heart disease, diabetes mellitus, hypertension, obesity, allergic rhinitis, and atopic sensitization.

At the time of admission, the presence of concurrent pneumonia or upper respiratory infections, oxygen saturation, blood pressure, heart rate, respiratory rate, body temperature, laboratory data, and spirometry results were evaluated. Also, clinical information obtained during the admission period, such as, the duration of systemic steroid administration for an asthma exacerbation, use of antibiotics, response to antibiotics, and the serial PFT results were assessed. The presence of upper respiratory infection at the time of admission was evaluated with a nasopharyngeal swab for respiratory virus PCR. Response to antibiotics was considered positive if there was improvement in chest $\mathrm{X}$-ray findings or a decline in CRP (C-reactive protein) levels during the admission period.

We performed univariate and multivariate analyses using the clinical variables listed above to determine risk factors associated with the prolonged recovery time of pulmonary function. We divided the study subjects into 2 subgroups based on the degree of adherence to ICS and performed subgroup analysis in patients who used ICS regularly.

\section{Statistical analysis}

Statistical analysis was performed using the Statistical Package for Social Sciences (SPSS) 20.0 software (IBM Corp., Armonk, NY, USA). Data with a normal distribution are expressed by using mean \pm standard deviation (SD) values. Summary statistics are presented as proportions (with $95 \%$ confidence intervals [CIs]). For categorical variables, the association between the recovery time of pulmonary function and variables was examined using chi-square or Fisher's exact tests. For continuous variables, the association between the recovery time of pulmonary function and variables was examined using Student's $t$ test after testing the data for normality. Multivariate linear regression was performed to examine independent factors associated with the recovery time of pulmonary function. Variables associated with pulmonary function recovery at the $P<0.05$ level in univariate analysis were considered for inclusion in multivariate analysis. All beta-coefficients are presented with 95\% CIs. All $P$ values were 2 -tailed, with $P<0.05$ considered statistically significant.

\section{RESULTS}

\section{Study patient characteristics}

The mean age of the patients was $57.6 \pm 17.9$ years (range, 1895 years), and $67.4 \%$ of the patients were female. Approximately $61.8 \%$ of patients had a previous history of an acute exacerbation, and $21.4 \%$ were hospitalized for uncontrolled asthma in the past year. Two-thirds of the patients had allergic rhinitis. Current smokers were composed $13 \%$ of all study subjects. Oth- 
Table 1. Baseline characteristics of the study patients

\begin{tabular}{lc}
\hline Characteristics & N (mean \pm SD/\%) \\
\hline Age & $89(57.6 \pm 17.9)$ \\
Female & $60(67.4)$ \\
Previous history of acute exacerbation & $55(61.8)$ \\
Regular use of ICS before exacerbation & $58(65.2)$ \\
Systemic steroid use for asthma in the past year & $45(50.6)$ \\
Hospitalization for asthma in the past year & $19(21.4)$ \\
Seasonal tendency of asthma exacerbation & \\
March-May & $22(25.0)$ \\
June-August & $14(15.9)$ \\
September-November & $16(18.2)$ \\
December-February & $36(41.0)$ \\
Concomitant disease & \\
Ischemic heart disease & $8(9.0)$ \\
Diabetes mellitus & $16(18.0)$ \\
Hypertension & $28(31.5)$ \\
Obesity (BMI) & $36(40.4)$ \\
Allergic rhinitis & $58(65.2)$ \\
Atopic sensitization & $12(13.5)$ \\
Smoking & \\
Non-smoker & $54(60.2)$ \\
Ex-smoker & $23(25.8)$ \\
Current smoker & $12(13.5)$ \\
\hline
\end{tabular}

er sociodemographic and baseline clinical characteristics are presented in Table 1.

\section{Recovery time of pulmonary function}

A total of 89 patients showed a wide range of recovery times of pulmonary function. The mean recovery time was 1.7 weeks. The recovery time showed a normal distribution after natural log transformation as confirmed by the Shapiro-Wilk normality test. Natural log-transformed pulmonary function recovery times were used for all of the subsequent analyses in this study.

\section{Analysis of factors influencing recovery time}

Clinical and laboratory characteristics of the patients at the time of admission are presented in Table 2. The best value of pulmonary function and serial pulmonary lung functions of individual patients at the time of admission and discharge are listed in Table 3. Univariate linear regression analysis showed that regular ICS use before an asthma exacerbation, presence of concurrent viral infection at admission, and lower FEV1\% predicted at the time of discharge were likely to prolong the recovery time of pulmonary function. By contrast, allergic rhinitis tended to shorten the recovery time (Supplemental Table 1).

Multivariate linear regression analysis was carried out using the variables that displayed a $P$ value $<0.05$ in univariate analysis. Multivariate analysis exhibited that patients who used ICS
Table 2. Characteristics of the study patients at the time of admission

\begin{tabular}{lc}
\hline Characteristics & $\mathrm{N}(\%)$ \\
\hline Needs for $\mathrm{O}_{2}$ & $19(21.4)$ \\
Concurrent pneumonia & $18(20.2)$ \\
Concurrent viral infection & $24(32.0)$ \\
\hline & Mean $\pm \mathrm{SD}(\mathrm{n}=89)$ \\
\hline $\mathrm{O}_{2}$ saturation & $91.5 \pm 20.1$ \\
Systolic blood pressure & $130.5 \pm 21.3$ \\
Diastolic blood pressure & $80.1 \pm 13.6$ \\
Heart rate (beats/min) & $98.6 \pm 17.9$ \\
Respiratory rate (breaths/min) & $21.9 \pm 4.9$ \\
Body temperature $\left({ }^{\circ} \mathrm{C}\right)$ & $36.8 \pm 0.7$ \\
WBC count $\left(\times 10^{3} / \mu \mathrm{L}\right)$ & $10.4 \pm 4.4$ \\
CRP count $(\mathrm{mg} / \mathrm{dL})$ & $3.3 \pm 5.4$ \\
\hline & Mean $\pm \mathrm{SD}(\mathrm{n})$ \\
\hline IgE count $(I \mathrm{U} / \mathrm{mL})$ & $582.5 \pm 887.5(24)$ \\
Eosinophil count $(/ \mu \mathrm{L})$ & $353.0 \pm 550.3(10)$ \\
Sputum eosinophil count & $12.0 \pm 15.2(22)$ \\
Sputum neutrophil count & $65.1 \pm 23.8(22)$ \\
\hline
\end{tabular}

Table 3. The best value and values of function at the time of admission and discharge (Mean \pm SD [N=89])

\begin{tabular}{lccc}
\hline $\begin{array}{c}\text { Pulmonary } \\
\text { function }\end{array}$ & $\begin{array}{c}\text { Personal } \\
\text { best value }\end{array}$ & $\begin{array}{c}\text { Value at } \\
\text { admission }\end{array}$ & $\begin{array}{c}\text { Value at } \\
\text { discharge }\end{array}$ \\
\hline FEV1\% predicted & $74.8 \pm 19.1$ & $44.5 \pm 16.6$ & $64.5 \pm 17.8$ \\
FEV1/FVC (\%) & $72.5 \pm 19.4$ & $57.3 \pm 16.3$ & $68.0 \pm 19.1$ \\
\hline
\end{tabular}

regularly before an asthma exacerbation $(P=0.005)$ and concurrent viral infection at admission were associated with a prolonged recovery time of pulmonary function ( $P=0.008$, Table 4$)$. Regular ICS use was associated with a 0.62-point increase compared to irregular ICS use, and concurrent viral infection at admission was associated with a 0.61-point change in the logtransformed recovery time compared to the absence of concurrent viral infection.

Since adherence to controller medication is considered a critical factor influencing the lifetime clinical course of asthma, the study subjects were divided into 2 subgroups according to the degree of medication adherence. The recovery time of pulmonary function in the 2 groups is shown in Figure. The sociodemographic and baseline clinical characteristics of the patients were compared between regular ICS users and irregular ICS users (Supplemental Table 2). The regular ICS users were associated with older age, previous history of an acute exacerbation, systemic steroid use, and history of hospitalization for asthma in the past year. The incidence of underlying ischemic heart disease (IHD) was significantly higher and the incidence of atopic sensitization was significantly lower in the regular ICS users. Regular ICS use was also associated with concurrent 
Table 4. Multivariate linear regression analysis of factors associated with a longer recovery time of pulmonary function after an acute asthma exacerbation

\begin{tabular}{lccc}
\hline Variable & $\begin{array}{c}\text { Beta } \\
\text { coefficient }\end{array}$ & $95 \% \mathrm{Cl}$ & $P$ value \\
\hline $\begin{array}{l}\text { Regular use of ICS before } \\
\text { exacerbation }\end{array}$ & 0.62 & $-0.19-0.55$ & $\mathbf{0 . 0 0 5}$ \\
$\begin{array}{l}\text { Concurrent viral infection } \\
\text { Allergic rhinitis }\end{array}$ & 0.61 & $0.18-1.04$ & $\mathbf{0 . 0 0 8}$ \\
\hline
\end{tabular}

Log-transformed values were used for the recovery time of pulmonary time of pulmonary function.

Table 5. Multivariate linear regression analysis of the subgroup of regular ICS users

\begin{tabular}{lccr}
\hline Variable & $\begin{array}{c}\text { Beta } \\
\text { coefficient }\end{array}$ & $95 \% \mathrm{Cl}$ & $P$ value \\
\hline Combined viral infection & 0.97 & $0.46-1.49$ & $<\mathbf{0 . 0 0 1}$ \\
Needs for $\mathrm{O}_{2}$ at admission & 0.11 & $0-1.36$ & 0.126 \\
FEV1\% predicted at discharge & -0.19 & $-0.02-0$ & 0.361 \\
\hline
\end{tabular}

pneumonia, lower $\mathrm{O}_{2}$ saturation, lower systolic and diastolic BP at admission, and lower FEV1\% predicted at discharge.

Subgroup analysis was performed for patients who used ICS regularly before an acute exacerbation of asthma. Univariate linear regression analysis showed that requirement for inhaled oxygen at admission, concurrent viral infection at admission, and lower FEV1\% predicted at discharge were likely to prolong the recovery time of pulmonary function (Supplemental Table 3). Multivariate analysis using variables selected at a $P$ value of $<0.05$ in the univariate analysis showed that only concurrent viral infection at admission was associated with a 0.97 -point increase in the log-transformed recovery time of pulmonary function $(P<0.001)$ (Table 5).

\section{DISCUSSION}

The results of our study indicated that patients with an asthma exacerbation showed a wide range of recovery times to reach the best FEV1 and that regular use of ICS and concurrent upper respiratory infection at admission were associated with a prolonged recovery time of pulmonary function. Although further studies are warranted, we could speculate that there would be a certain unknown subtype of asthma associated with the prolonged recovery time of pulmonary function after an acute exacerbation despite regular ICS use.

Asthma exacerbations are possibly life-threatening and can be a significant burden that leads to hospitalization, decline in lung function, and high medical costs. Asthma exacerbations are usually induced by exposure to external triggers, such as viral upper respiratory infection, pollens, and air pollution, although some exacerbations occur without specific causes. Poor

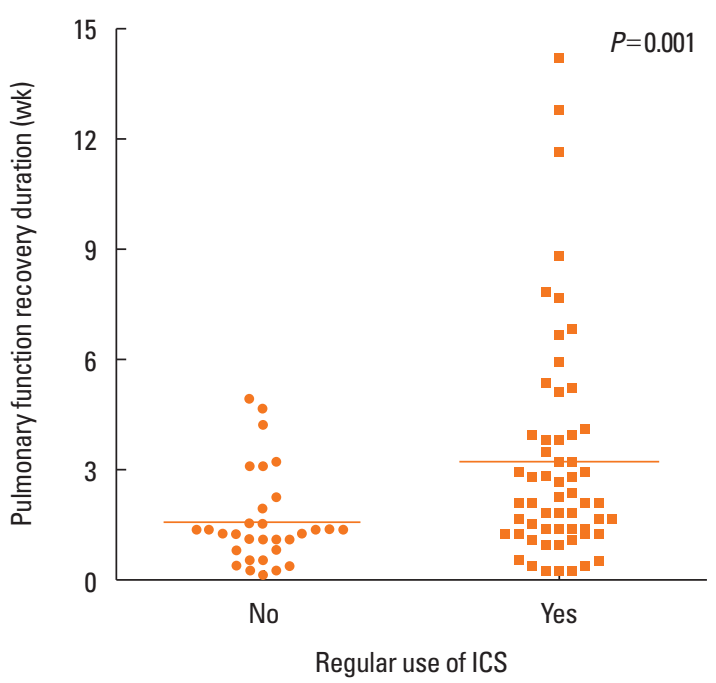

Figure. Dot plot of recovery time duration according to regular ICS use. Patients who used regular ICS showed a longer pulmonary function recovery time compared to those who did not.

adherence to medication could also be a critical factor linked to asthma exacerbations. ${ }^{1,2,5,6}$ In addition to the diversity of causes of asthma exacerbations, the clinical courses of recovery from an exacerbation are also variable. A previous study has reported that PFT parameters usually return to their baseline values within 1-2 weeks after an asthma exacerbation. ${ }^{8}$ However, we see a wide range of time lapse from the administration of therapeutic agents to full recovery in patients with an asthma exacerbation. Delayed recovery is expected to increase the burden of asthma. In fact, a severe asthma exacerbation is clearly associated with a rapid decline in lung function, ${ }^{4,6}$ and a longer time of asthma exacerbations is likely to be associated with a poorer clinical course of asthma in the long-term follow-up. Thus, factors affecting recovery from an asthma exacerbation should be identified and managed because the factors presumably will have a great impact on outcome of asthma treatment.

In our analyses, the recovery time of pulmonary function after an asthma exacerbation was remarkably variable, ranging from 1 day to 14 weeks. Our findings are consistent with those of previous studies that reported recovery of pulmonary function after a moderate to severe asthma exacerbation required more than 7 days in two-thirds of children and longer than 14 days in one-fourth of children. ${ }^{13}$ The frequency of acute asthma exacerbations is considered a critical factor affecting the phenotypes of asthma; however, recovery time after an asthma exacerbation has not been considered an important factor for defining asthma subtypes. Although further clarification is required, investigation on the influence of various recovery patterns on asthma phenotypes would be a valuable approach to manage asthma exacerbations.

Although recent studies have improved our understanding of the complexity of inflammatory pathways involved in asthma 
exacerbations and their potential relationship with lung function ${ }^{8,15}$ factors critically linked to poor recovery from asthma have not been clearly defined. In our study, regular ICS use and concurrent viral upper respiratory infection at admission were found to be linked to the prolonged recovery time of pulmonary function. Several other studies have also investigated factors affecting recovery time after an asthma exacerbation. In one of these studies, allergic rhinitis was suggested to be a significant factor affecting the recovery time of pulmonary function in children with a moderate to severe asthma exacerbation. ${ }^{13}$ Interestingly, in our study patients with allergic rhinitis tended to display even a shorter recovery time of pulmonary function. The reason for this discordant result may have been attributed to the difference in the study populations, although further studies are warranted. Another study indicated that several factors, including age $>40$ years, non-atopic asthma, longer duration of an acute exacerbation before hospital admission, poor long-term control of asthma, and use of maintenance oral corticosteroids, were associated with the prolonged recovery time of pulmonary function. ${ }^{14}$ These results differ from ours, which might be attributed to the different ethnic backgrounds and clinical situations between the 2 groups of study subjects. Regarding the use of oral corticosteroids, only a few patients on maintenance oral corticosteroids were included in our study.

Regular ICS use before an asthma exacerbation was found to be an important factor for a longer recovery time in our study. It is reasonable to presume that regular ICS use is not directly associated with the prolonged recovery time after an asthma exacerbation. Rather, we speculate that regular ICS use is linked to a unique subtype of asthma showing differences in its underlying severity and responsiveness to ICS. In fact, corticosteroid resistance has been reported in a small group of asthmatic patients with poorly controlled asthma who showed reversibility to inhaled $§$-agonists, but not to high-dose oral corticosteroid. ${ }^{16}$ Asthmatic patients with corticosteroid resistance more frequently show differences in pathologic features, including greater thickness of the airway epithelium and basement membrane, than corticosteroid-sensitive asthmatic patients. ${ }^{17}$ Further studies are needed with a larger number of patients to clarify the role of corticosteroid resistance.

The results of our study also indicated that viral respiratory infection was associated with prolonged recovery time after an asthma exacerbation. Viral respiratory infections are obvious triggers for asthma exacerbations, ${ }^{3,18,19}$ however, there is some controversy as to whether these viral infections affect the recovery time after an acute exacerbation of asthma. Previous studies have reported that the severity of asthma exacerbations is significantly associated with viral respiratory infections. ${ }^{19-23}$ Moreover, less responsiveness to beta 2 agonists has been reported in acute asthmatics with symptoms of viral respiratory infection. ${ }^{22}$ In contrast, another study has indicated that the presence of viral respiratory disease does not influence recovery from an asthma exacerbation in non-hospitalized patients. ${ }^{21}$ Further investigations are needed to clarify the effects of viral respiratory infections on recovery from asthma exacerbations.

Our findings also showed that regular ICS users who were older and had more frequent asthma exacerbations and hospitalization in the past year were more frequently treated with systemic steroids. The incidence of underlying ischemic heart disease was significantly higher and the incidence of atopic sensitization was significantly lower in patients who used ICS regularly. Regular ICS users also typically showed more requirement for inhaled oxygen, concurrent pneumonia at admission, lower $\mathrm{O}_{2}$ saturation, lower $\mathrm{BP}$ at admission, and lower FEV1\% predicted at the time of discharge. Therefore, our data suggest that the regular ICS user group may have included more severe asthmatics who showed a poorer response to ICS and a longer recovery time.

With regard to ICS use in asthmatics, adherence to ICS is a critical factor for the clinical course of asthma. Subgroup analysis of regular ICS users was performed in our study. Univariate linear regression analysis showed that the need for inhaled oxygen, concurrent viral infection at admission, and lower FEV1\% predicted at the time of discharge were likely to prolong the recovery time of pulmonary function. However, only concurrent viral infection at admission was found to be associated with the prolonged recovery time of pulmonary function in the multivariate linear regression analysis.

There are several limitations of our study. First, this is a retrospective study, so PFTs were not performed in all cases. This may have caused some inaccuracy in determining the precise day reaching the best FEV1. In addition, the treatment of individual patients was also not standardized. Secondly, the best FEVl value analyzed in this study may have been inaccurate. The data on adherence to asthma medication and magnitude of compliance in individual patients may have been precise because they were determined by self-reporting at the time of admission. Thirdly, our investigation was performed only for hospitalized patients. Given that a larger number of patients with an acute asthma exacerbation were managed in the outpatient clinic and even at the patient's home through self-management instructions, the findings of our study may only represent the characteristics of a small proportion of asthmatic patients.

In summary, the recovery time of pulmonary function after an acute exacerbation of asthma varied among patients who were hospitalized. Regular ICS use before an acute exacerbation of asthma with concurrent viral infection at admission was an important factor for the recovery time of pulmonary function. A longer recovery time after a severe asthma exacerbation was not significantly associated with poor adherence to ICS. The results of this study indicate that the recovery time after an acute exacerbation of asthma may be prolonged despite regu- 
lar ICS use probably due to corticosteroid resistance in subtypes of asthma.

\section{REFERENCES}

1. Global Initiative for Asthma. Global strategy for asthma management and prevention [Internet]. [place unknown]: Global Initiative for Asthma; 2014 [updated 2015 Aug 12; cited 2015 Nov 25]. Available from: http://www.ginasthma.org/.

2. Ye YM, Kim SH, Hur GY, Kim JH, Park JW, Shim JJ, et al. Addition of montelukast to low-dose inhaled corticosteroid leads to fewer exacerbations in older patients than medium-dose inhaled corticosteroid monotherapy. Allergy Asthma Immunol Res 2015;7:440-8.

3. Rodrigo GJ, Rodrigo C, Hall JB. Acute asthma in adults: a review. Chest 2004;125:1081-102.

4. Martinez FD, Vercelli D. Asthma. Lancet 2013;382:1360-72.

5. O'Byrne PM, Pedersen S, Lamm CJ, Tan WC, Busse WW; START Investigators Group. Severe exacerbations and decline in lung function in asthma. Am J Respir Crit Care Med 2009;179:19-24.

6. Song WJ, Cho SH. Challenges in the management of asthma in the elderly. Allergy Asthma Immunol Res 2015;7:431-9.

7. Guilbert TW, Denlinger LC. Role of infection in the development and exacerbation of asthma. Expert Rev Respir Med 2010;4:71-83.

8. Cohn L, Woodruff PG. Update in asthma 2013. Am J Respir Crit Care Med 2014;189:1487-93.

9. Donahue JG, Weiss ST, Livingston JM, Goetsch MA, Greineder DK, Platt R. Inhaled steroids and the risk of hospitalization for asthma. JAMA 1997;277:887-91.

10. Debley JS, Cochrane ES, Redding GJ, Carter ER. Lung function and biomarkers of airway inflammation during and after hospitalization for acute exacerbations of childhood asthma associated with viral respiratory symptoms. Ann Allergy Asthma Immunol 2012; 109:114-120.e2.

11. Peters SP, Ferguson G, Deniz Y, Reisner C. Uncontrolled asthma: a review of the prevalence, disease burden and options for treatment. Respir Med 2006;100:1139-51.

12. Racusin DA, Fox KA, Ramin SM. Severe acute asthma. Semin Perinatol 2013;37:234-45.
13. Szefler SJ, Martin RJ, King TS, Boushey HA, Cherniack RM, Chinchilli VM, et al. Significant variability in response to inhaled corticosteroids for persistent asthma. J Allergy Clin Immunol 2002;109: 410-8.

14. Martin RJ, Szefler SJ, King TS, Kraft M, Boushey HA, Chinchilli VM, et al. The predicting response to inhaled corticosteroid efficacy (PRICE) trial. J Allergy Clin Immunol 2007;119:73-80.

15. Yilmaz O, Bakirtas A, Ertoy Karagol HI, Topal E, Demirsoy MS. Allergic rhinitis may impact the recovery of pulmonary function tests after moderate/severe asthma exacerbation in children. Allergy 2014; 69:652-7.

16. Jenkins PF, Benfield GF, Smith AP. Predicting recovery from acute severe asthma. Thorax 1981;36:835-41.

17. Holt PG, Strickland DH. Interactions between innate and adaptive immunity in asthma pathogenesis: new perspectives from studies on acute exacerbations. J Allergy Clin Immunol 2010;125:963-72.

18. Schwartz HJ, Lowell FC, Melby JC. Steroid resistance in bronchial asthma. Ann Intern Med 1968;69:493-9.

19. Cohen L, E X, Tarsi J, Ramkumar T, Horiuchi TK, Cochran R, et al. Epithelial cell proliferation contributes to airway remodeling in severe asthma. Am J Respir Crit Care Med 2007;176:138-45.

20. Greenberg S. Asthma exacerbations: predisposing factors and prediction rules. Curr Opin Allergy Clin Immunol 2013;13:225-36.

21. Matsumoto K, Inoue H. Viral infections in asthma and COPD. Respir Investig 2014;52:92-100.

22. Silva RC, Couceiro JN, Câmara FP, Valle S, Santos N. Asthma exacerbation and viral infection in adult patients, Brazil. Braz J Infect Dis 2015;19:446-8.

23. Chang AB, Clark R, Acworth JP, Petsky HL, Sloots TP. The impact of viral respiratory infection on the severity and recovery from an asthma exacerbation. Pediatr Infect Dis J 2009;28:290-4.

24. Rueter K, Bizzintino J, Martin AC, Zhang G, Hayden CM, Geelhoed $\mathrm{GC}$, et al. Symptomatic viral infection is associated with impaired response to treatment in children with acute asthma. J Pediatr 2012; 160:82-7.

25. Arden KE, Chang AB, Lambert SB, Nissen MD, Sloots TP, Mackay IM. Newly identified respiratory viruses in children with asthma exacerbation not requiring admission to hospital. J Med Virol 2010; 82:1458-61. 